\title{
Different transitions: Timetable failures in the transition to school
}

\author{
Lina Lago
}

Linköping University Post Print

\section{Tweet}

N.B.: When citing this work, cite the original article.

Original Publication:

Lina Lago , Different transitions:Timetable failures in the transition to school, 2016, Children \& society.

http://dx.doi.org/10.1111/chso.12176

Copyright: Wiley: 24 months

http://eu.wiley.com/WileyCDA/

Postprint available at: Linköping University Electronic Press

http://urn.kb.se/resolve?urn=urn:nbn:se:liu:diva-129928 


\begin{abstract}
The aim of this article is to show how transitions are constructed, and to discuss different ways of making the transition from the preschool class to first grade. The analysis is grounded in ethnographic fieldwork. Temporality is used to understand expectations about how transition should be made. The results reveal that some children made their transitions in ways that did not follow the expected timetable. These transitions can be understood as timetable failures, and needed to be made sense of by both children and teachers. These different transitions were an important part of the overall construction of transition.
\end{abstract}

\title{
Keywords
}

Transition, education, temporal order, timetable, childhood 


\section{Introduction}

In this article, theories of time are used to understand the transition from the preschool class to first grade. The main objective is to understand the transition with a focus on children whose pattern of transition can be said to deviate from the 'normal' transition. The aim is to show how transitions are constructed by children and adults in school.

Children's transitions and early encounters with school are important in relation to their knowledge about school, and how they make sense of school. Previous research indicates that starting school is crucial to how children perceive school (Einarsdóttir, 2010) and that how children's school life starts can have an impact on their school performance (Pollard and Filer, 1999). The preschool class and the transition to school raise questions about expectations, norms, and what it is to be a child in school. This article focuses on occasions when such expectations or norms are broken.

The preschool class was introduced in Sweden in 1998. It is a voluntary year of school that most Swedish children attend the year they turn six. The preschool class is governed by certain parts of the compulsory school curriculum: it is subject to the parts about values and overall goals and guidelines but not to the goals of attainment. It often take place on primary school premises. From a general perspective, starting school in Sweden might seem quite straightforward. In August, thousands of six-year-olds start preschool class. One year later, these same children begin the compulsory primary school. On closer examination, the start of school is revealed to be more complex. The preschool class itself can be said to contribute to this. It is not entirely clear whether the preschool class or first grade is the 'real' start of school, since most - but not all children attend preschool class. Other reforms that make it easier to start compulsory school at age six and give greater possibilities to choose schools have also contributed to this differentiation of starting school. This means that some children's schooling and school start occur on a different timetable than the majority. Previous research has shown that even if starting school is differentiated or staggered for some children, it is often treated by the school as if it were the same (Lago, 2014). 


\section{Theoretical framework}

A starting point is to study how children and adults together create meanings in interaction, how they define the situations in which they participate, and how well such definitions are negotiated (Blumer 1969; James and others, 1998; Jenkins 1996). Such a focus on relationships and meaning-making processes is well suited to the aim of this study since it focuses on how transitions are constructed in interaction.

\section{Doing transitions}

A transition can be said to be a time of change. In this study transitions are seen as processes over time, as such they include the temporal aspects before, during and after an actual change has occurred (Fabian 2007; Lam and Pollard 2006; Niesel and Griebel 2007). This means that transitions consist of both actual events and the processes of giving these events meaning. To be part of and managing a transition can be summarized by Schwartzman's (1978, p. 326) words about transformation, it is about "turning the novel into the familiar". The focus of this article is on how transitions are constructed in interactions between activities, actions and speech of individuals (children and teachers) within an institutional context. During these interactions, rules and norms are made visible and are negotiated (Corsaro and Molinari, 2005; Holstein and Gubrium, 2000).

In transitions, individuals' different understandings interplay with context and structure in the meaning-making processes. This makes institutional markers of transition and the experiences and actions of individuals equally important in understanding how transitions are made. Structures for transitions provide opportunities for changes in status, and experiences, actions and understandings of change influence the structures of transition (Corsaro and Molinari, 2005; Ecclestone and others, 2010). In transition processes, ideas of what school is, is not, and can be, are negotiated and transformed. According to Adam (1995), norms of time are an important part of school. In school transitions, children and teachers need to understand and communicate the school's rules and norms. The social meaning of time creates conditions for transitions. Time is a vital part of the school order through, for example, the organisation of the school year and the scheduling of the school day. Time is here considered to be a result 
of social agreements, which means that the meaning of time changes between contexts. Time is both something that is used by people, and something that constitutes frames for people's actions (Adam, 1995). The analysis and findings in this article build on the notions of temporal order and timetables. Both can be used to describe the time norms in school.

\section{Temporal order}

Temporal order is how a context, in this case school, is understood through the use of time within that context (Adam, 1995; Zerubavel, 1981). School time is the result of the history of school and is also established by the individuals who, by choice or by constraint, constitute school. In Roth's (1963: 73) words, 'It [school] is a system in which the pupils, their parents, the teacher, and anyone else concerned agrees on the reference points as well as the end-point in the timetable'.

Zerubavel (1981) divides temporal order into four different aspects. The first aspect is sequential structure: the order in which activities or events take place. Zerubavel argues that social institutions such as school are often characterised by a strong sequential structure. Time in school should be used in specific ways; otherwise, we do not recognise it as school. The second aspect that contributes to temporal order is duration: how long something is expected to last. The third aspect is temporal location: when something occurs. The final aspect is rate of recurrence: how often and at what intervals activities are expected to recur.

These expectations can also be discussed in terms of timetables. Roth (1963) uses the term 'timetable' to describe time norms and expectations about how time should be used in contexts with an expected progression - such as school. A timetable is defined as the 'normal' temporal order of an event, including expectations of how long it will last, in what order things will occur and when it is reasonable for this event to take place. A timetable related to schooling would thus include norms about when children are expected to start school, which grade comes first, and so on (Hockey and James, 1993; Sutton and others, 2013). In relation to timetables, the concept of timing (the 'right' content, at the 'right' time and at the 'right' pace) becomes important. There is a 'proper time' for different events (Zerubavel, 1981: 8). Consequently, normality and deviance are constructed on the basis of such timetables. Holstein and Gubrium (2000: 
79) define this as being 'on time' or 'off time' in relation to a timetable. Deviations, or timetable failures, occur when individuals or their actions do not follow the expected use of time. According to Roth (1963: 106), when timetables are not followed, individuals try to find explanations in order to somehow understand this failure or give this deviation meaning.

\section{Research context}

As mentioned, this article is concerned with transitions that do not follow the expected patterns. Some research exists on these and other transitions. Research on school transitions deals with everything from conditions for transitions (Sabol and Pianta, 2012) to how transitions are made in everyday life (Corsaro and Molinari, 2005; Lago, 2015). This study aims to contribute with knowledge about how the conditions for transitions are used when understanding transitions in children’s everyday life.

This article uses the concept of timetable failures to understand deviating transitions. This way of studying deviations from normal progress was introduced by Roth in his book Timetables (1963). He uses this concept to describe health-related processes such as recoveries and patient careers. However, he also uses the concept of timetables to talk about the use of time in educational settings. As a result of Roth's research, some health care-related research has been done that uses the concept of timetable failures (e.g. Coffey, 2013). In educational research, the concept of timetable failures is rarely used, even though considerable research exists on topics that can be understood as such. When it comes to research on deviating transitions or school experiences, grade retention is a well-researched area. Many of the studies on grade retention are longitudinal and focus on long-term outcome for these children (Gottfried, 2013; Martin, 2011). There is also research on school entry age with relevance for this study since it concerns children who deviate from the school start timetable. In their study of redshirting (keeping children at home and letting them start school late), Graue and DiPerna (2000) showed that a delayed school entry has some impact on school results. 
In educational research, there are few studies on how timetable failures are managed by children in everyday life. In recent years, interest in children's views on and how they manage transition has increased, the number of studies that focus on how transitions are accomplished by those involved is growing, and questions about how children manage and talk about transition have caught the interest of an increasing number of researchers (cf. Corsaro and Molinari, 2005; Perry and others, 2014; Lago, 2015). Deviating transitions, however, are not paid much attention and there are therefore few studies to mention. In her study on how children manage friendships during transition Weller (2007) shows that those who move alone to a school are more likely to struggle with their friendships during and after a transition. Messiou and Jones (2013) interviewed students about their views on transferring schools in the middle of the semester. Students described their concerns about their social relationships but also stated that it could mean a fresh start academically. In a previous study on starting school in Sweden, Lago (2014) showed that transition trajectories vary within a given group of pupils. In a seemingly homogenous group of children there were children who had experienced grade retention, skipped classes, or were 'late starters'. This article builds on the results from this study by further examining children's different transitions using theories of temporal order. By doing so, this article contributes to current research with further perspectives on how transitions are given meaning in everyday life.

\section{Method}

To study how children make sense of timetable failures during their transition from the preschool class to first grade, ethnographic methods were used (participant observations and interviews), following a group of 25 children and their teachers at the André School (pseudonym). The fieldwork was conducted between February and October 2010. The observations were documented with field-notes while the interviews were recorded. Closeness is crucial for an ethnographic approach (Hammersley and Atkinson, 2007), since it leads to a better understanding of, for example, how the concrete processes of giving meaning to transitions take place. Interacting with children and adults allows such closeness to the participants. This makes ethics important in ethnographic fieldwork as there are both formal and informal ethical issues to consider. A letter of consent containing information about the study was distributed to the guardians who 
gave written consent for their children to participate. The children and their teachers gave their consent verbally. Children have no formal right to give consent but, since their participation was vital, their informal consent was important. Pseudonyms are used for people and places to protect the identity of the participants.

Data were analysed by being coded and categorised into themes to get a systematic and comprehensive overview of the data. In this article, themes concerning children's deviating experiences of transitions are analysed further. Ethnographic analysis is used to addresses "the issue of 'what is going on' between the participants" (Wilkinson, 2011: 169) using examples of events relevant to these themes. The result of the ethnographic analysis is presented under the headings: Failing the sequential structure, Failing temporal location: Doing transition at the wrong time, Failing temporal location: Doing transition at the wrong age, and Making sense of timetable failures.

\section{Analysis and findings}

Most of the children at the André School made the transition from the preschool class to first grade together, in the same way and at the same time. Their transition can be described as a transition according to the timetable of the institution. Their transition followed the expected sequential structure: they were preschool class children who became first graders. The duration of the transition was timed: they spent no more and no less than 10 months in the preschool class. Their transition had the expected temporal location, both within their time in school and within their life course: the pupils' individual transitions were made at the same time, from the same starting-place to the same ending-place; the transitions followed the pace of the school year; and the children made their transitions at the same, and expected, age. Finally, these children's transitions followed the expected rate of recurrence; they made this transition once.

However, for some children, the transition to first grade looked different. Their transitions deviated from this expected transition and can be described as being 'off time' in one way or another. These transitions did not follow the expected timetable of transition, the school year or the time in school. These transitions can be described, using Roth’s (1963) concept, as timetable failures. The results presented below show 
different ways in which children made transitions that can be seen as deviating from the norm and how to make sense of these deviations.

\section{Failing the sequential structure}

One expectation of a timetable-appropriate transition is that it is made in the same way by all the children in the group. Some children at the André School deviated from this by not following the rest of the group during the transition.

Example 1

It is one of the first days in first grade. We are on their way to a nearby park. Jabir and the teacher, Pia, walk at the end of the line. Jabir asks Pia where Tomas is. 'He has moved to another city', Pia responds. 'Tilde then?' asks Jabir. 'She has also moved and changed schools', answers Pia.

Tilde and Tomas were two of the children who somehow deviated from the expected collective transition from the preschool class to first grade. In relation to the schedule (the combination of when and where), one can be 'off place' (in an unexpected location, Cresswell, 1996) as well as being 'off time'. Jabir's questions to Pia show that he expected Tomas and Tilde to be in the same place as him; otherwise, he would not have missed them. Jabir noticed Tilde's and Tomas' absence and tried to make sense of it hence asking the question. Transitioning to the wrong place was one way in which children deviated from the timetable of transition. Several children did not return to the André School after the summer break; others began in other groups and some were new in first grade. These children made their transitions in different ways from the majority.

As mentioned above, a transition that follows the timetable of school follows the sequential structure, the order in which activities take place. Children start as preschool class children and move on to become first graders, second graders and so on. There were a few children in the group who did not follow this sequential structure. Markus was one of them.

Example 2 
I sit down beside Sofi and Markus. Markus looks up. 'Do you know how old I am?' he asks. 'Eight', I answer. 'Yes, because I've stayed back a year because I can't read', says Markus. 'Yes, that's how it is sometimes', I reply. 'What?' Sofi asks, looking up from her book. 'Nothing', I say. Markus smiles and says nothing.

Markus was one of the new children in the group in first grade. He had moved there from another school, making his transition different. Making a transition alone can influence children's friendships and thus makes it a different transition than a transition made together with others (cf. Weller, 2007). Markus' transition was also different in another way, as he explained, it was the second time he had begun first grade. Markus' school transition did not follow the expected sequential structure where you are a preschool class child, then a first grader, and then a second grader. By being a first grader who became a first grader, Markus failed the timetable of school by attending first grade twice rather than moving forward. Markus' mentioning of his age and his statement 'I’ve stayed back a year because I can't read' can be seen as a way to make sense of his different transition and explain to me why he is old-for-grade. According to Adam (1995), these expectations of school's temporal order are strong and not following them is therefore noticeable, hence the need to explain. Sofi's interest in the conversation can be interpreted as an interest in the subject itself, i.e. deviating from the expected is out of order and therefore noteworthy.

Markus' transition was a timetable failure since it did not follow the expected rate of recurrence. A transition that follows the 'normal' timetable takes place once. The practice of grade retention was also used in some other cases. Grade retention is a type of timetable failure that is visible to other children. Their visibility made such deviations from 'normal' transition an important part of how the transition was understood by all the children. In an interview, done in first grade, Manda talks about Tobias.

Example 3

Me: $\quad$ Okay. Anything else in first grade that's not as you thought? 
Manda: That we would (pause) that we would, uh, when Tobias came back to preschool class. That could happen to us.

Manda talked about the risk of being moved from first grade back to the preschool class. She referred to Tobias, a child who had such an experience. In Manda's comment, the expected sequential structure is not the only possible sequential structure. School progress becomes less certain: instead of continuing forward through the grades, schooling may take a different direction. When different transitions became visible to the other children, grade retention became a risk for them too. Coming 'back to preschool class' was not something that was restricted to Tobias, as Manda's 'that could happen to us' shows. In this way, Tobias' experience became a shared experience and different transitions like his were made part of the local peer culture. In Manda's meaning-making, the strong sequential structure of school grade levels became weakened.

Timetable failures like grade retention were talked about both by the children who were 'failing' and by the other children. Sometimes a timetable failure was something negative, as in example 3, but the children also treated it as a resource: this is analysed further later on. The teachers rarely spoke of different transitions when they addressed the whole group. Different transitions became a subject for the teachers when children asked about them, but even in these situations the teacher did not always address the different transitions. The 'normal' transition, however, was talked about by the teachers in an instructive way. At the end of the year in the preschool class, the teachers talked about what would happen after the summer break. They did this addressing the whole group, even though the whole group was not affected. The different transitions were more visible when the children made sense of transition than when the teachers did.

\section{Failing temporal location: Doing transition at the wrong time}

Another form of timetable failure was connected to the passing of the school year. The Swedish school year runs from August to June and has a great impact on children's schooling, and certain season-specific activities such as Easter and summer break help to mark the passing of time. In this timetable of school, the 'normal' transition takes 
place over the summer and although almost all the children in the group changed grades over the summer not all did.

Example 4

It's the middle of May, and it is circle time in the preschool class. Someone asks where Fouad is; he hasn't attended preschool class for a few days. 'He's in first grade', says the teacher, Kajsa. 'Why is he in first grade?' the children want to know. 'He is in the international class, it's like first grade', says Kajsa. 'Fouad is older than you', she adds.

The fact that the children asked about Fouad's whereabouts indicates that his absence was unexpected. This (unexpected) change must be understood and given meaning. Being absent from the group without a reasonable explanation was not consistent with the temporal order of school. Fouad's transition can be said to deviate from the 'normal' transition's temporal location. It can be seen as being 'off time' to change grades in the middle of the school year and Fouad can be said to fail the temporal location, i.e. when transition should occur. This kind of timetable failure constitutes a deviation from the group's collective progress since they involve different occasions than the norm. When Fouad deviated from the expected timing of transition and from the rhythm of the group, other understandings of time and transitions became possible and a different transition was made.

\section{Failing temporal location: Doing transition at the wrong age}

Age was another aspect of temporal order that was made relevant to the timing of transition. In the following example, the expectations that are tied to age and the transition to first grade are made visible by Theresa, a substitute teacher in the preschool class.

\section{Example 5}

It's Sofi's seventh birthday. Pia, the teacher, has gone to get matches so she can light the birthday candle. Theresa asks the children if anyone else has turned seven yet. 'I have! I have!' several children cry out. 'I'm almost eight and a half', Abbas says. 'I've also turned eight!', says Tobias. 'No, really?' 
Theresa looks at them. 'Have you? You cannot be eight', she adds. The other children confirm that Abbas and Tobias are eight. 'Jelica, raise your hand!' says Vanna, looking at Jelica. 'Are you seven too?', Theresa asks Jelica. 'Yes, she is', Vanna replies. 'I'm a hundred years old', says Ammar. 'I'm nine!', Tomas says, and stretches to become taller. When Pia gets back, Theresa asks her: 'Are any of the children eight years old?'. Pia nods.

Theresa questioned the children's claims about their ages. As a substitute teacher she was not familiar with the local order at the André School where some children attended the preschool class even if they were not six years old. In the example, Theresa shows strong ideas of a 'right' age to be in a particular grade; otherwise, she would not have had anything to question. The timetable of school is linked to age and the life course (Hockey and James, 1993; Holstein and Gubrium, 2000). When children do not follow the expected progress, the deviation from the norm can be considered a timetable failure related to temporal location. Theresa's objection that the children 'cannot be eight' while attending the preschool class is one example of these time and age norms. The way that school is organised affects the expectations of at what age children are expected to attend certain grades. School has a transition structure that is associated with age and the way school is organised provides conditions for an expected life course within school. These expectations caused the children who were eight or nine to deviate from the norms of age and school progress, as expressed by Theresa. Theresa can be said to use age in a developmental way (ideas of development being part of the timetable of school [Hockey and James 1993]) to understand which children belong in which grade. The older children were, in her eyes, 'off time'. In the example, the children resisted and negotiated these age norms. They played with age and with Theresa's expectations by claiming that they were eight, nine or even a hundred years old. Age was a complicated issue, since some children were not the expected six or seven years old. Due to grade retention, skipped classes, or being 'late starters', several children did not make an 'on time' transition. These old-for-grade children were breaking the temporal order in relation to their entire school careers: they were 'off time' in relation to the temporal location and the 'wrong' age for the preschool class. 


\section{Making sense of timetable failures}

The children discussed transitions 'off time', to a greater extent than transitions 'on time'. This can be understood as a way the children made sense of events that did not follow their expectations of how things should be. Processes that follow the expected course do not need to be understood and given meaning in the same way as deviations. It is changes that cause a need to understand and give meaning to what has changed. In examples 1 and 4, it is a 'loss' that causes the children to ask about other pupils. Manda's talk in example 3 about Tobias' grade retention being something that might affect others in the group can also be understood as such meaning-making. In the following example, Tobias' talk about his experience of first grade can be seen as another way to create meaning about timetable failures.

Example 6

It's circle time in the preschool class. Tobias raises his hand and is given the chance to speak. 'When I'm in first grade, I can help with maths because I know the whole book'. 'That's good', the teacher, Kajsa, answers. 'Then you can be a teacher's assistant and help Anita just like Leo does'. 'Well, not the whole book', adds Tobias. 'I haven't done the whole book. I can only help with the parts that I had time to do'.

Tobias called attention to his experience of having been in first grade before. He and other children who were 'off time' did this sometimes. At first, I found it surprising that being 'off age' or making the transition in the 'wrong' way was used by the children as something positive. However, this positive connection to a previous experience of first grade or to being older can be understood as a claim of competence. In this example, Tobias referred to his greater knowledge in maths, and connected this knowledge to his previous experience of first grade maths and knowing 'the whole book'. He argued, and was supported by the teacher, Kajsa, that this made him more competent than his classmates: he was so skilled that he could 'help with maths' in first grade. This way of speaking of his own competence became a way to show that he was an initiated and more experienced member, i.e. someone who knew and understood the local order in 
first grade. By his comments, Tobias showed that he knew what first grade was about and he portrayed himself as an expert on first grade maths.

The case of being older than the other children in a grade can also be understood in relation to the status that follows with higher age in childhood (Hockey and James, 1993). Calling attention to higher age, as the children do in example 5, can be understood in a similar way to Tobias' claim. If higher age in itself is of positive value, and is connected to benefits such as greater skills and maturity, it is reasonable for children to speak up and say that they are older than their classmates. This is true even if these children attend the preschool class rather than the 'proper' grade for their age. The way that the children talked about and used age reflected that for them the expected connections between age and grade were not present. Age and grade are predetermined on an institutional level, but not on an individual level.

These ways of using something potentially negative as a resource are ways to manage deviations from the collective transition and give that timetable failure meaning. Being retained was a risk when it came to the future (see Manda's comment in example 3), but could still be used as a resource in the present. Being old-for-grade was not necessarily something negative; on the contrary, it could be used to gain status.

\section{Conclusions}

Returning to the aim, to show how the temporal order of school is used in the construction of transitions, the results show that the transition from the preschool class to first grade was made in several different ways. The timetable was made visible by being broken. Within the same group of children, the ways of making the transition varied, and the 'normal' transition did not apply to all children. The social order of school thus becomes important in the construction of different transitions. The 'normal' transition had an impact on the transitions that were different, since it was what the teachers mainly talked about, and seemed to assume for all children. When they were made visible, mainly (though not only) by the children, the different transitions broadened the pre-existing ideas about what transition might be, and what was considered possible. In this way, the transition from the preschool class to first grade became a more complex process. 
The different transitions were mainly discussed as part of the local peer culture and as such were an important part of how 'normal' transition was constructed. The transitions that were 'off time' impacted how transitions 'on time' were understood and vice versa. The impact of the 'on time' transition on the deviant transitions can be seen in the expectations that the children and teachers expressed. When they spoke about transition, they expressed their expectations of how it should be and of an expected timetable for transition, with a specific sequential structure, duration, temporal location, and rate of recurrence. When these expectations were not met, both children and teachers needed to make sense of what had happened, leading to their recognition of different transitions. For example, the absence of some children was recognised because there was an expectation that all children should be in the same place at the same time. Statements about age can be understood in a similar way. There cannot be timetable failures without a timetable, no 'wrong' without a 'right'.

The conclusion from the study is that to understand and to be able to work with the complexity of transition processes, it is important to pay attention to different transitions. Otherwise, they will never be a shared part of children's and teachers' everyday lives. If they continue to be only a part of children's peer cultures, the meanings made will not be shared. If meaning-making is seen as a collective process where individual experiences as well as context and structure are important, the way adults talk about children's transitions is important for how children make transitions and vice versa. In school, adults can be seen as representatives of the school as such and what they say and what they do not say, what they do and what they do not do become important. To connect children's meanings with school context, children's different experiences need to be made visible; otherwise, the different transitions might appear to be random and something that 'could happen to us'. Unless different transitions are made visible and become an integral part of the common story of the transition from the preschool class to first grade, teachers might miss out on the more positive use of timetable failures. A timetable failure then risks becoming an actual failure rather than part of a complex process where deviation can be both a risk and a resource.

\section{References}

Adam B. 1995. Timewatch: The Social Analysis of Time. Polity: London. 
Blumer H. 1969. Symbolic Interactionism: Perspective and Method. University of California Press: Berkeley.

Coffey M. 2013. Time and its uses in accounts of conditional discharge in forensic psychiatry. Sociology of Health \& Illness 35(8): 1181-1195. DOI: 10.1111/14679566.12036

Corsaro WA, Molinari L. 2005. I Compagni: Understanding Children's Transition from Preschool to Elementary School. Teachers College Press: New York.

Cresswell T. 1996. In Place/Out of Place: Geography, ideology, and transgression. University of Minnesota Press: Minneapolis.

Ecclestone K, Biesta G, Hughes M 2010. Transitions in the lifecourse: The role of identity, agency and structure. In Transitions and learning through the lifecourse. Ecclestone K, Biesta G, Hughes M (eds). Routledge: London; 1-15.

Einarsdóttir J. 2010. Children's experiences of the first year of primary school. European Early Childhood Education Research Journal 18(2): 163-180. DOI: $10.1080 / 13502931003784370$

Fabian H. 2007. Informing transitions. In Informing Transitions in the Early Years: Research, Policy and Practice. Dunlop A-W, Fabian H (eds). McGraw-Hill/Open University Press: Maidenhead; 3-17.

Gottfried MA. 2013. Retained students and classmates' absences in urban schools. American Educational Research Journal 50(6): 1392-1423. DOI: $10.3102 / 0002831213498810$

Graue EM, DiPerna J. 2000. Redshirting and Early Retention: Who Gets the "Gift of Time" and What Are Its Outcomes? American Educational Research Journal 37: 509534, DOI: 10.3102/00028312037002509

Hammersley M, Atkinson P. 2007. Ethnography: Principles in Practice. Routledge: Milton Park, Abingdon, Oxon. 
Hockey J, James A. 1993. Growing Up and Growing Old: Ageing and Dependency in the Life Course. Sage: London.

Holstein JA, Gubrium JF. 2000. Constructing the Life Course. General Hall Inc.: New York.

James A, Jenks C, Prout A. 1998. Theorizing Childhood. Polity Press: Cambridge.

Jenkins R. 1996. Social identity. Routledge: London.

Lago L, 2014. "Mellanklass kan man kalla det”: Om tid och meningsskapande vid övergången från förskoleklass till årskurs ett. Linköping: Linköpings Universitet.

Lago L, 2015. Time for transition: The use of future in the transition from preschool class to first grade. International Journal of Transitions in Childhood, 7: 26-34.

Lam MS, Pollard A. 2006. A conceptual framework for understanding children as agents in the transition from home to kindergarten. Early Years 26(2): 123-141. DOI: $10.1080 / 09575140600759906$

Martin AJ. 2011. Holding back and holding behind: grade retention and students' nonacademic and academic outcomes. British Educational Research Journal 37(5). DOI: $10.1080 / 01411926.2010 .490874$

Messiou K, Jones L. 2013. Pupil mobility: using students' voices to explore their experiences of changing schools. Children \& Society, DOI: 10.1111/CHSO.12026

Niesel R, Griebel W. 2007. Enhancing the competence of transition systems through coconstruction. In Informing Transitions in the Early Years: Research, Policy and Practice. Dunlop A-W, Fabian H (eds). McGraw-Hill/Open University Press: Maidenhead; 21-32.

Perry B, Dockett S, Petriwskyj A. (eds). 2014. Transitions to school international research, policy and practice. Dordrecht: Springer.

Pollard A, Filer, A. 1999. The Social World of Pupil Career: Strategic Biographies Through Primary School. Cassell: London. 
Roth JA. 1963. Timetables: Structuring the Passage of Time in Hospital Treatment and Other Careers. The Bobbs-Merrill company, Inc.: Indianapolis.

Sabol TJ, Pianta, RC. 2012. Patterns of school readiness forecast achievement and socioemotional development at the end of elementary school. Child Development 83(1): 282-299.

Schwartzman HB. 1978. Transformations: The anthropology of children's play. Plenum Press: New York.

Sutton A, Muller C, Langenkamp, AG. 2013. High school transfer students and the transition to college: Timing and the structure of the school year. Learning Sociology of Education 86(1): 63-82. DOI: 10.1177/0038040712452889

Weller S. 2007. 'Sticking with your mates?': children's friendship trajectories during the transition from primary to secondary school. Children \& Society, 21: 339-351. DOI:10.1111/j.1099-0860.2006.00056.X

Wilkinson S. 2011. Analysing focus group data. In Qualitative research: Issues of theory, method and practice. Silverman D (eds). London: SAGE; 158-184.

Zerubavel E. 1981. Hidden Rhythms: Schedules and Calendars in Social Life. University of California Press: Berkeley. 